\title{
Identifying potential RNAi targets in grain aphid (Sitobion avenae F.) based on transcriptome profiling of its alimentary canal after feeding on wheat plants
}

\author{
Min Zhang ${ }^{1 \dagger}$, Yuwen Zhou ${ }^{2 \dagger}$, Hui Wang ${ }^{1}$, Huw Dylan Jones ${ }^{3}$, Qiang Gao ${ }^{2}$, Dahai Wang ${ }^{1}$, Youzhi Ma ${ }^{1 *}$
} and Lanqin $\mathrm{Xia}^{1 *}$

\begin{abstract}
Background: The grain aphid (Sitobion avenae F.) is a major agricultural pest which causes significant yield losses of wheat in China, Europe and North America annually. Transcriptome profiling of the grain aphid alimentary canal after feeding on wheat plants could provide comprehensive gene expression information involved in feeding, ingestion and digestion. Furthermore, selection of aphid-specific RNAi target genes would be essential for utilizing a plant-mediated RNAi strategy to control aphids via a non-toxic mode of action. However, due to the tiny size of the alimentary canal and lack of genomic information on grain aphid as a whole, selection of the RNAi targets is a challenging task that as far as we are aware, has never been documented previously.
\end{abstract}

Results: In this study, we performed de novo transcriptome assembly and gene expression analyses of the alimentary canals of grain aphids before and after feeding on wheat plants using Illumina RNA sequencing. The transcriptome profiling generated 30,427 unigenes with an average length of $664 \mathrm{bp}$. Furthermore, comparison of the transcriptomes of alimentary canals of pre- and post feeding grain aphids indicated that 5490 unigenes were differentially expressed, among which, diverse genes and/or pathways were identified and annotated. Based on the RPKM values of these unigenes, 16 of them that were significantly up or down-regulated upon feeding were selected for dsRNA artificial feeding assay. Of these, 5 unigenes led to higher mortality and developmental stunting in an artificial feeding assay due to the down-regulation of the target gene expression. Finally, by adding fluorescently labelled dsRNA into the artificial diet, the spread of fluorescence signal in the whole body tissues of grain aphid was observed.

Conclusions: Comparison of the transcriptome profiles of the alimentary canals of pre- and post-feeding grain aphids on wheat plants provided comprehensive gene expression information that could facilitate our understanding of the molecular mechanisms underlying feeding, ingestion and digestion. Furthermore, five novel and effective potential RNAi target genes were identified in grain aphid for the first time. This finding would provide a fundamental basis for aphid control in wheat through plant mediated RNAi strategy.

Keywords: Grain aphid (Sitobion avenae F.), Alimentary canal, Transcriptome profile, Double strand RNA (dsRNA), Artificial feeding assay, RNA interference (RNAi), Aphid control

\footnotetext{
*Correspondence: mayouzhi@caas.cn; xialanqin@caas.cn

${ }^{\dagger}$ Equal contributors

'Institute of Crop Sciences, Chinese Academy of Agricultural Sciences (CAAS),

12 Zhongguancun South Street, Beijing 100081, China

Full list of author information is available at the end of the article
} 


\section{Background}

Aphids are major agricultural pests which cause significant yield losses of the crop plants each year by inflicting damage, both through the direct effects of feeding and by vectoring debilitating plant viruses $[1,2]$. Annual worldwide crop losses due to aphids are estimated at hundreds of millions of dollars [3-5]. The aphid species infesting wheat in China include grain aphid (Sitobion avenae F.), greenbug (Schizaphis graminum Rondani), Rhopalosiphum padi Linnaeus and Metopolophium dirhodum Walker. Of these, the grain aphid is the most dominant and destructive, affecting $65 \%$ of wheat production areas in China [6]. Grain aphid is also the major pest of wheat in Europe and North America [7]. For the last few decades, conventional breeding programs have been undertaken in an attempt to increase wheat aphid resistance worldwide [7]. However, due to the lack of effective aphid resistant germplasm, the complexity of plant-aphid interactions and the rapid development of resistant pest biotypes, outbreak of aphids causing substantial losses of wheat continue to be reported regularly $[7,8]$. Breeders and growers are still struggling to find an efficient genetic strategy for aphid control in wheat [8].

Expression in transgenic plants of double stranded (ds)RNA designed against insect target genes has been shown to give protection against pests through RNA interference (RNAi), opening the way for a new generation of insect-resistant crops [9-11]. In the case of plant-mediated RNAi for insect control, both cell-autonomous and non-cell-autonomous RNAi are required for the persistence of RNAi effect. For cell-autonomous RNAi, the silencing process is limited to the cell in which the dsRNA is introduced, expressed and encompasses the RNAi process within individual cells [12-16]. The interfering effect of non-cell-autonomous RNAi, can take place in tissues/cells different from the location of application or production of the dsRNA. There are two different kinds of non-cell-autonomous RNAi: environmental RNAi and systemic RNAi. Environmental RNAi describes all processes in which dsRNA is taken up by a cell from the environment [17]. Systemic RNAi refers to all processes in which the silencing signal is transported from the cell in which the dsRNA is applied or expressed to other cells and tissues in which the silencing could take place [18-20]. In multicellular organisms, environmental RNAi can be followed by systemic RNAi and non-cell-autonomous RNAi will always be followed by cell-autonomous RNAi [12]. At least two mechanisms underlying RNAi in insects have been described so far, that is, the transmembrane channel-mediated uptake mechanism and an alternative endocytosis-mediated uptake mechanism [12]. In aphid, except the existence of SID-1 which is a multispan transmembrane protein mediating a systemic RNAi effect, the uptake mechanism of dsRNA remains to be determined [12,21]. Nevertheless, RNAi-mediated knockdown of C002, a gene strongly expressed in the salivary glands of A. pisum have led to death of aphids through direct injection of siRNA into aphid hemolymph [22]. V-ATPase is a membrane-bound protein that acts as a proton pump to establish the $\mathrm{PH}$ gradient within the gut lumen of many insects. Knockdown of $v$ ATPase transcripts following feeding on $v A T$ Pase dsRNAs also led to significant mortality of A. pisum [23]. Furthermore, injection of dsRNA targeting genes encoding a calcium-binding protein calreticulin and a gut cathepsin, and feeding dsRNA of a water-specific aquaporin gene in artificial diet assay led to the downregulation and malfunction of these targeted genes in A. pisum, although the target gene expression knockdown didn't exceed $50 \%$ and was transient, persisting for less than a week $[24,25]$. So far, two cases of plant-mediated RNAi for aphid control have also been reported. Silencing COO2 gene and a gut-specific gene Rack-1 in peach aphid resulted in the knock down of these two genes by up to $60 \%$ after feeding on transgenic tobacco and Arabidopsis plants, with affected aphids producing less progeny [26]. Host-generated siRNAs attenuated the expression of a serine proteinase gene in peach aphid, leading to a significant reduction in their fecundity and parthenogenetic population upon feeding on transgenic Arabidopsis plants [27]. These two cases exemplify the feasibility of plantmediated RNAi approach for aphid control in agriculture. However, up to now, RNAi and plant-mediated RNAi for aphid control have not been documented in grain aphid nor has the systemic RNAi effect been observed previously in aphid species.

Illumina RNA sequencing (RNA-seq) enables the de novo reconstruction of the transcriptome for a nonmodel organism and also acts as a potentially effective way to identify RNAi targets by mass-screening of candidate genes in organisms with insufficient genomic information [28-32]. The midgut of Hemipterans and most other insects is lined by the perimicrovillar membrane (PMM) [33]. Hence, the midgut is the only portion of an insect's body that has an active interface with the physical environment. The cells of the midgut, which are responsible for nutrient absorption from the gut lumen, can take up dsRNA and are one of the routes through which RNAi could be achieved in insects [12,34].

In this study, RNA-seq was used to investigate the transcriptome profile of the alimentary canal of grain aphid upon feeding on wheat plants. Comparison of the transcriptome profiles of the alimentary canals of preand post-feeding grain aphid on wheat plants revealed insights into the involvement of diversified genes and/or pathways. Furthermore, the systemic RNAi effect was investigated for the first time in grain aphid. Novel and effective RNAi target genes were explored through a dsRNA artificial diet feeding assay and candidate genes were identified that could act as potential targets for plant-mediated RNAi control of aphids in wheat. 


\section{Results}

Analyses of the differentially expressed genes in the alimentary canal of grain aphid after feeding on wheat plants revealed the involvement of diversified genes and/or pathways in ingestion and digestion

To obtain a global view of the transcriptome profiles of the alimentary canals of grain aphids upon feeding, the alimentary canals of pre- and post-feeding grain aphids which were derived from a single clonal lineage were dissected for RNA isolation. High-throughput RNA-seq was performed by Illumina RNA sequencing in BGIShenzhen. After filtering out the adaptors and low quality sequences, 26.3 and 25.7 million clean reads with a total read-length over 2.4 and 2.3 billion nucleotides respectively, were obtained from the alimentary canals of grain aphids pre-feeding (DuiZhao) [NCBI: SRA accession number SRX216768] and $6 \mathrm{~h}$ after feeding (ChuLi) [NCBI: SRA accession number SRX216767]. These reads were subsequently assembled into contigs and then unigenes using SOAPdenovo software. In total, 32,714 and 35,267 unigenes were obtained for ChuLi and DuiZhao with a mean length of 501 and $493 \mathrm{bp}$, respectively. The unigenes from the two samples were then clustered using TGI clustering tools (TGICL) [35] and further assembled with Phrap Assembly Program (http://www.phrap.org), resulting in a total of 30,427 unigenes with mean length of 664 bp (Table 1). Of these unigenes, 20,736 (68.1\%) had NCBI non-redundant protein database (nr) annotations as determined by BLAST search. Clusters of orthologous groups (COG), gene orthology (GO), and Kyoto Encyclopedia of Genes and Genomes (KEGG) annotations were performed to better understand the functions of these unigenes (data not shown).

The expression levels of the unigenes in post-feeding (Chuli) and pre-feeding (Duizhao) grain aphids were estimated based on RPKM (Reads Per kb per Million Reads) analysis [36]. In total, 5490 genes were found to be differentially expressed, among which, 2918 genes were up-regulated whereas 2572 genes were down-

Table 1 Summary of the transcriptomes of the alimentary canal of grain aphid upon feeding on wheat

\begin{tabular}{llll}
\hline & $\begin{array}{l}\text { Duizhao } \\
\text { (pre-feeding) }\end{array}$ & $\begin{array}{l}\text { Chuli } \\
\text { (post-feeding) }\end{array}$ & All \\
\hline Total number of reads & $26,285,658$ & $25,667,932$ & \\
Total nucleotides (nt) & $2,365,709,220$ & $2,310,113,880$ & \\
Total number of contigs & 93,174 & 83,219 & \\
Total number of scaffolds & 44,170 & 40,497 & 30,427 \\
Mean length of scaffolds (bp) & 421 & 432 & 664 \\
Total unigenes & 35,267 & 32,714 & \\
Mean length of unigenes (bp) & 493 & 501 & $44.12 \%$ \\
GC percentage & $42.19 \%$ & & \\
\hline
\end{tabular}

regulated (FDR $<0.001$ and an absolute value of the $\log 2$ ratio $>1$ ) (Figure 1). Besides, among the differentially expressed genes (DEGs), there were 34 genes only expressed in Chuli and 234 genes only expressed in Duizhao (See Additional file 1).

For these DEGs, nr, COG, GO, and KEGG annotations were performed. Of these 5490 DEGs, only 3805 were annotated in at least one of the above public databases (Figure 2). Annotation details of these DEGs were as listed in Additional file 1. For example, only 733 had GO annotations (See Additional file 2). Whereas there were no presence of significantly enriched cellular components, three molecular functions were found to be enriched at $\mathrm{p}<0.05$ level, including NADH dehydrogenase activity, oxidoreductase activity, acting on NADH or $\mathrm{NADPH}$, quinone or similar compound as acceptor, and $\mathrm{NADH}$ dehydrogenase (quinone) activity. Eight biological processes were significantly enriched $(\mathrm{p}<0.05)$ including organ morphogenesis, organ development, generation of precursor metabolites and energy, imaginal disc development, cellular respiration, system development, oxidation-reduction process, energy derivation by oxidation of organic compounds. The enriched KEGG pathways upon feeding were as listed in Additional file 3. Among them, of the 2021 unigenes involved in 'Metabolic pathways' (ko01100), 420 showed differentially expressed manner, accounting for $18.09 \%$ of total DEGs (2322) with pathway annotation.

Analyses of 16 highly up-regulated and down-regulated genes in grain aphid upon feeding and characterization of their tissue-specific expression manner

To screen for potential RNAi target genes in grain aphid, 16 candidate genes which were highly expressed (based on their RPKM values) in both Chuli and Duizhao, or only expressed in one treatment, were selected for further confirmation of their actual expression levels in aphids after feeding on wheat plants and dsRNA artificial diet feeding assay (Table 2). The qRT-PCR analysis confirmed the DEGs analysis results of these selected genes in grain aphid upon feeding on wheat plants, with the relative expression levels of 8 unigenes $(8273,11975$, 23028, 23235, 26956, 27882, 28447 and 28469) altered very significantly after feeding (**Student's t-test, $\mathrm{n}=3$, $\mathrm{p}<0.01$ ), whereas that of another 4 unigenes (8279, 21088, 21789 and 29689) also changed significantly but had a lower probability value ("Student's t-test, $\mathrm{n}=3, \mathrm{p}<$ 0.05) (Figure 3). Furthermore, semi-quantitative RT-PCR analyses of different aphid tissues (head, alimentary canal and fat body without alimentary canal) showed that the selected unigenes were expressed in the tested tissues at different levels except for unigenes 11975, 23235 and 27357 which could not be detected in head samples (Figure 4). 


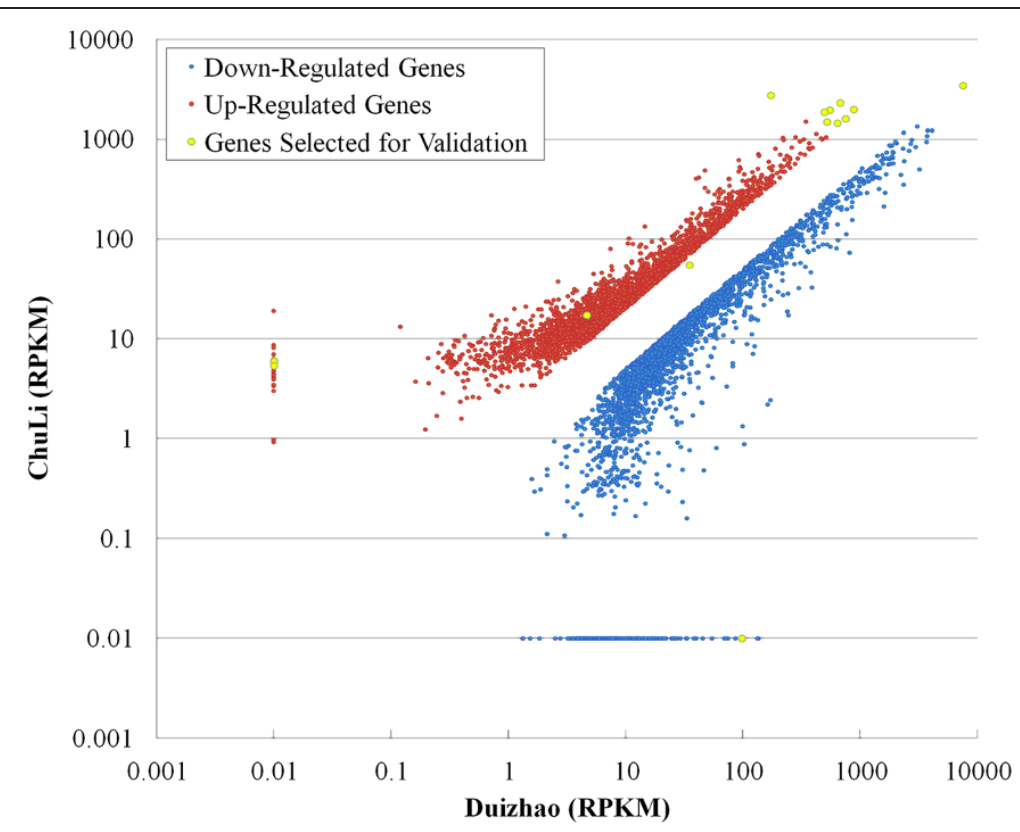

Figure 1 The relative expression levels of differentially expressed genes in grain aphid alimentary canal upon feeding. In total, 5490 genes were found to be differentially expressed among which up-regulated genes were indicated with purple points, whereas down-regulated genes with blue points. The selected 16 genes were indicated by yellow point.

\section{Screening for potential RNAi targets using an artificial} feeding assay and the effects of dsRNAs on aphid development and mortality

To screen for potential RNAi target genes in plantmediated RNAi for aphid control in wheat, dsRNAs of the 16 candidate RNAi target genes listed above was synthesized in vitro and incorporated into an artificial diet. COO2 is a gland-specific gene first isolated from the pea aphid and knock-down of this gene led to the death of pea aphid and improved peach aphid resistance in transgenic tobacco plants $[22,26]$. A homologue of C002 from grain aphid was identified and named as SaCOO2 in

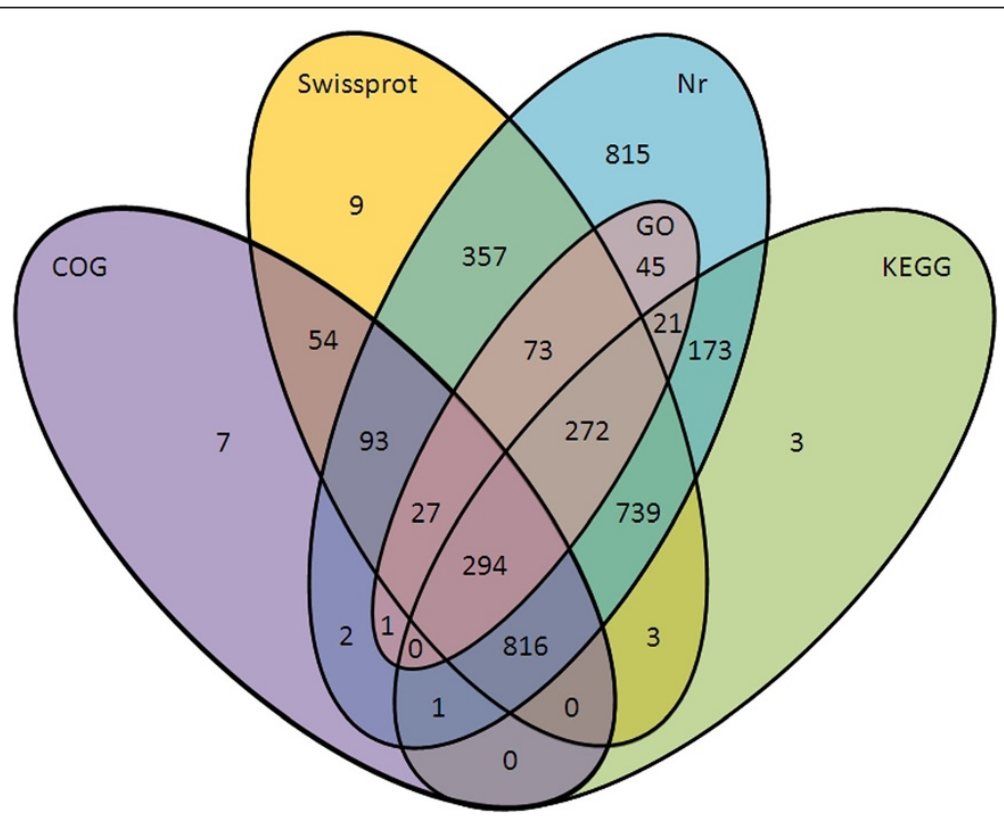

Figure 2 A Venn diagram illustrating shared and unique DEGs annotated in nr, Swissprot, COG, GO and KEGG public databases. Among 5490 DGEs, 3805 annotated in at least one of the public databases, including 3729, 237, 1295, 2322, 733 in nr, Swissprot, COG KEGG and GO databases, respectively. 
Table 2 Nr annotations and RPKM values of 16 selected candidate RNAi target genes in alimentary canal of grain aphid

\begin{tabular}{|c|c|c|c|c|}
\hline Unigene no. & Nr-annotation & $\begin{array}{l}\text { RPKM value of the } \\
\text { unigene in Chuli }\end{array}$ & $\begin{array}{l}\text { RPKM value of the } \\
\text { unigene in Duizhao }\end{array}$ & $\begin{array}{l}\text { Log } 2 \text { ratio } \\
\text { (Chuli RPKM/Duizhao RPKM) }\end{array}$ \\
\hline Unigene_6994 & Synaptotagmin 4 [Acyrthosiphon pisum] & 54.8647 & 35.322 & 0.64 \\
\hline Unigene_ 8273 & Similar to cuticular protein CPG12 [Acyrthosiphon pisum] & 1454.892 & 641.2085 & 1.18 \\
\hline Unigene_ 8279 & Similar to CG10625 [Acyrthosiphon pisum] & 1967.559 & 554.559 & 1.83 \\
\hline Unigene_11975 & Hypothetical repeat protein [Leishmania infantum] & 17.2449 & 4.6812 & 1.88 \\
\hline Unigene_21088 & $\begin{array}{l}\text { cytochrome c oxidase subunit VIlc precursor } \\
\text { [Acyrthosiphon pisum] }\end{array}$ & 3463.178 & 7555.03 & -1.13 \\
\hline Unigene_21789 & No orthologs identified & 1987.456 & 886.7044 & 1.16 \\
\hline Unigene_23028 & Similar to zinc finger protein [Acyrthosiphon pisum] & 6.0578 & 0.0 & Only in Chuli \\
\hline Unigene_23042 & $\begin{array}{l}\text { Similar to AGAP007992-PA, partial sequence } \\
\text { [Acyrthosiphon pisum] }\end{array}$ & 6.0346 & 0.0 & Only in Chuli \\
\hline Unigene_23235 & $\begin{array}{l}\text { Similar to defective proboscis extension response } \\
\text { [Tribolium castaneum] }\end{array}$ & 5.4287 & 0.0 & Only in Chuli \\
\hline Unigene_26956 & No orthologs identified & 0.0 & 98.1775 & Only in Duizhao \\
\hline Unigene_2 27357 & $\begin{array}{l}\text { Similar to proteophosphoglycan ppg1 } \\
\text { [Acyrthosiphon pisum] }\end{array}$ & 1481.846 & 525.2179 & 1.49 \\
\hline Unigene_2 27882 & $\begin{array}{l}\text { Similar to neurofilament, heavy polypeptide isoform } 2 \\
\text { [Acyrthosiphon pisum] }\end{array}$ & 1602.747 & 751.6207 & 1.09 \\
\hline Unigene_28447 & No orthologs identified & 1861.09 & 494.6134 & 1.91 \\
\hline Unigene_28469 & No orthologs identified & 2775.923 & 174.3591 & 3.99 \\
\hline Unigene_28555 & ACYPI002010 [Acyrthosiphon pisum] & 2321.885 & 681.4342 & 1.76 \\
\hline Unigene_29698 & No orthologs identified & 0.0 & 98.4885 & Only in Duizhao \\
\hline
\end{tabular}

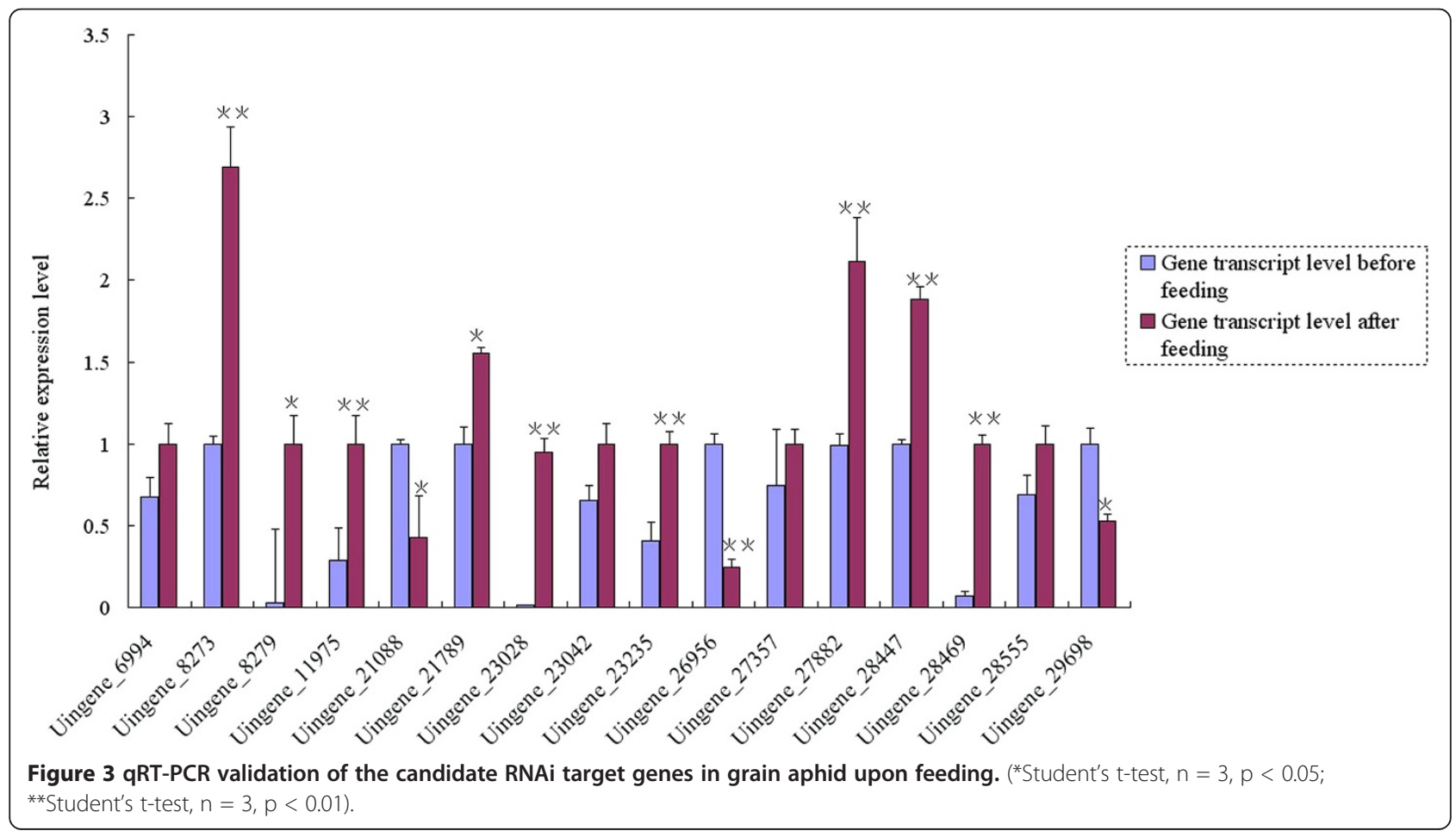




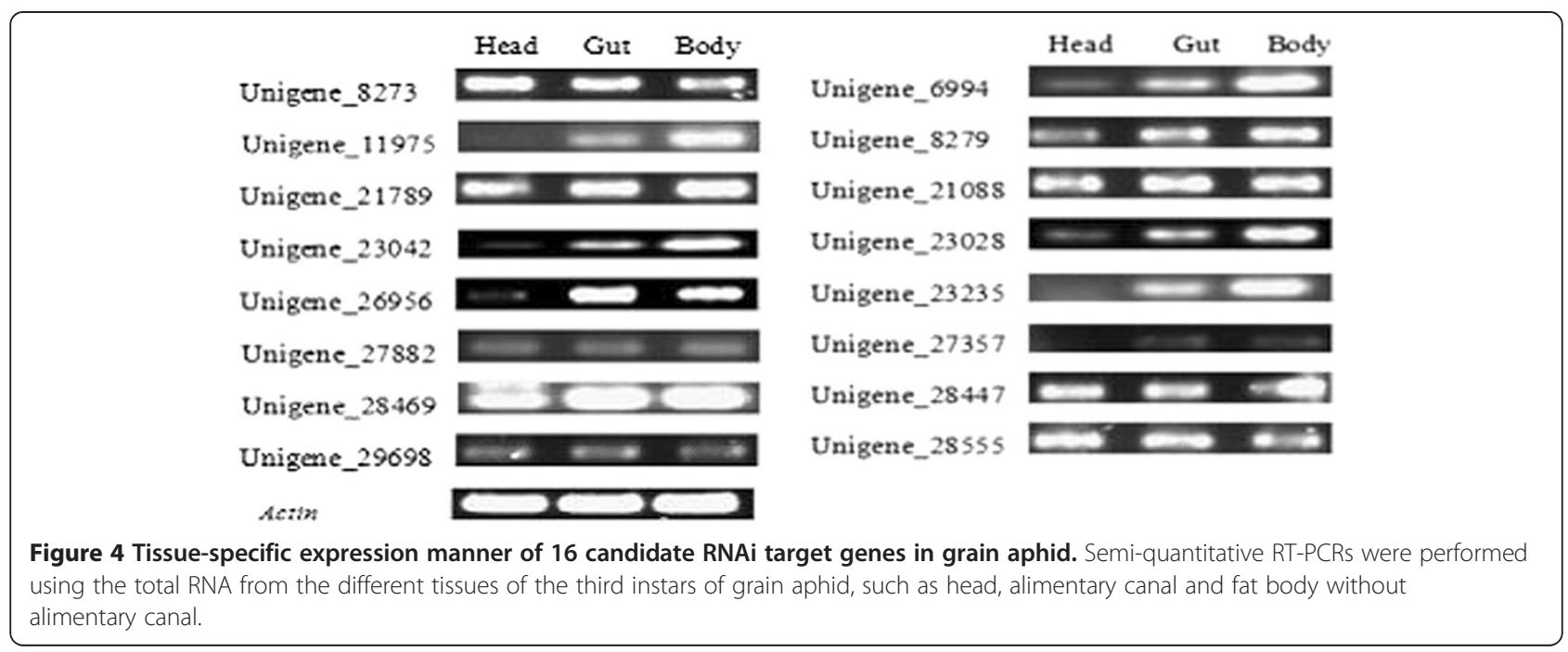

this study (data not shown). Then, a 284 bp dsRNA was in vitro synthesized and used as a positive control to test the efficacy of other candidate RNAi target genes in this study. First, in order to test the efficacy of dsRNA on the mortality of aphid and its specificity, the effects of different concentration of COO2 dsRNA and GFP dsRNA added to the artificial diet on the mortality of third instars of grain aphid at different time points were investigated. As shown in Figure 5, compared with blank artificial diet without any dsRNA (control), the GFP dsRNA in the artificial diet had no effect on the mortality of aphids, whereas the mortality of aphids correlated with both increased concentration of $\mathrm{COO} 2$ dsRNA and feeding time, reaching a very significant level at $8 \mathrm{~d}$ for the concentration of $5 \mathrm{ng} / \mu \mathrm{l}$, and 6 and/or $8 \mathrm{~d}$ for $7.5 \mathrm{ng} / \mu \mathrm{l}$. Therefore, we used the $7.5 \mathrm{ng} / \mu \mathrm{l}$ concentration of dsRNA to investigate the mortality of the third instars grain aphids feeding on artificial diet added with dsRNA of 16 selected candidate RNAi target genes. As indicated in Figure 5 and Figure 6, the dsRNA of GFP control had no effect on the mortality of aphid, indicating the lethality mentioned above was caused by sequence-

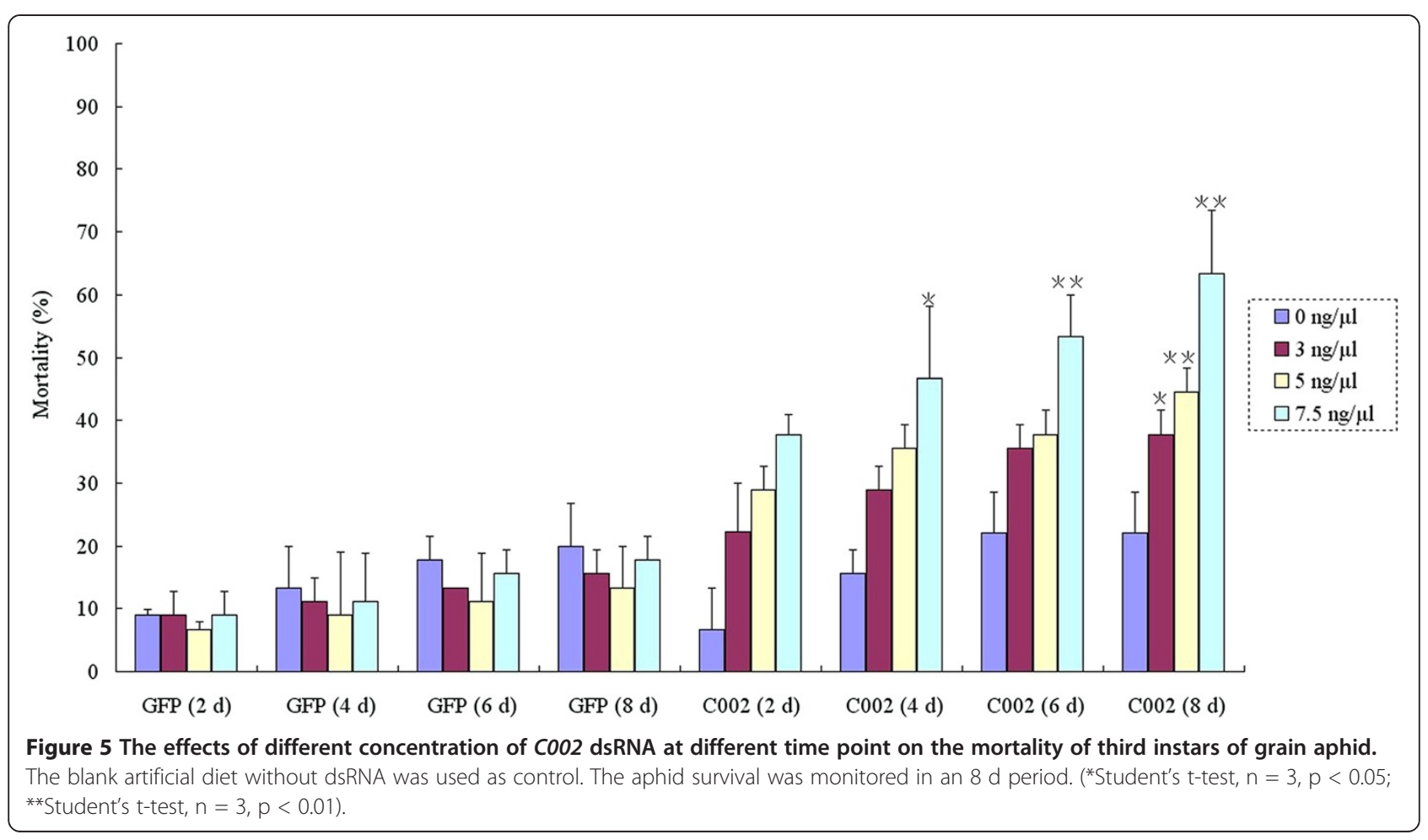




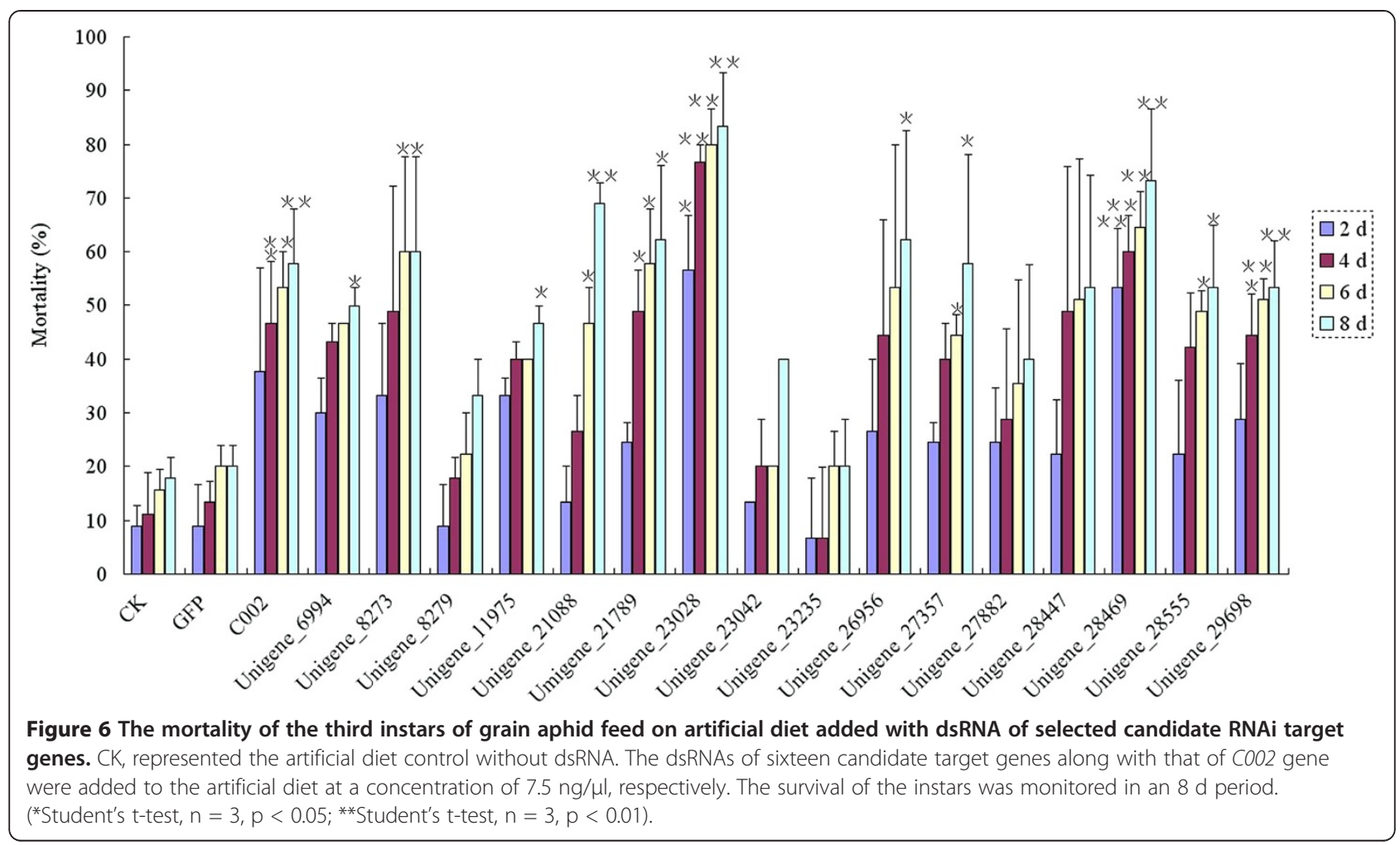

specific effect of the dsRNAs rather than by the physical or chemical characteristics of dsRNAs per se. When $7.5 \mathrm{ng} / \mu \mathrm{l}$ dsRNA was added to the artificial diet, $4 \mathrm{~d}$ later, the mortality levels of aphids fed with dsRNAs of COO2 and unigenes 21088, 21789, 23028, 28469 and 29698 were between $60 \%$ and $90 \%$ after correction. These data were statistically significant when compared with control treatments without dsRNA or with GFP dsRNA, and led to even higher mortality and developmental stunting than the positive control $\mathrm{COO} 2$ at day 8. The dsRNAs targeting the rest of the selected unigenes such as 6994, 8273, 11975, 26956, 27357 and 28555 also led to significant mortality either at day 6 or 8 . However, no big differences on mortality were found in the treatments with dsRNA targeting unigenes 8279, 23042, 23235, 27882 and 28447. In addition, except for unigenes 21088 and 23028 which were predicted to encode orthologs of a cytochrome c oxidase subunit VIIc precursor and a zinc finger protein in pea aphid, respectively, KEGG pathway analysis and BLASTX against the $\mathrm{nr}$ and ApdidBase database (www. aphidbase.com) didn't reveal any orthologs of 21789, 28469 and 29698 unigenes, suggesting they were novel or newly annotated genes/transcripts identified in grain aphid.

To investigate the correlation of larval mortality with the relative expression level of the respective target gene and to verify that administration of dsRNA does not affect the expression of household genes such as actin, five candidate RNAi target genes including the unigene 8273 which displayed highly up-regulated profile upon feeding on wheat plants (Figure 3) and other four unigenes 21088, 21789, 23028 and 28469 (Figure 6) were selected to detect their relative expression levels upon feeding on artificial diet added with the respective dsRNAs at different time point by using the aphid actin gene as internal control. The dsRNAs were supplied to the artificial diet at concentration of $7.5 \mathrm{ng} / \mu \mathrm{l}$. qRT-PCRs were performed using the total RNA from the surviving instars at different time points after feeding on the artificial diet. The relative expression levels of 5 RNAi target genes were monitored at indicated time point in an $8 \mathrm{~d}$ period. As indicated in Figure 7, the expression of unigenes 8273, 23028 and 28469 was knocked down significantly after dsRNA feeding at day 6 , with the latter two genes completely silenced at day $8\left({ }^{* * *}\right.$ Student's t-test, $\left.\mathrm{n}=3, \mathrm{p}<0.01\right)$. The expression levels of unigenes 21088 and 21789 increased 2 days after dsRNA feeding, and decreased in the following days, with that of unigene 21088 knocked down significantly at day 8 too ("Student's t-test, $\mathrm{n}=3, \mathrm{p}<0.05$ ). These results indicated that the mortality and developmental stunting caused by feeding these dsRNAs was due to the down-regulation and even silencing of the respective target gene. Combined with the results of mortality analysis, we would like to propose that unigenes 8273, 21088, 23028, 


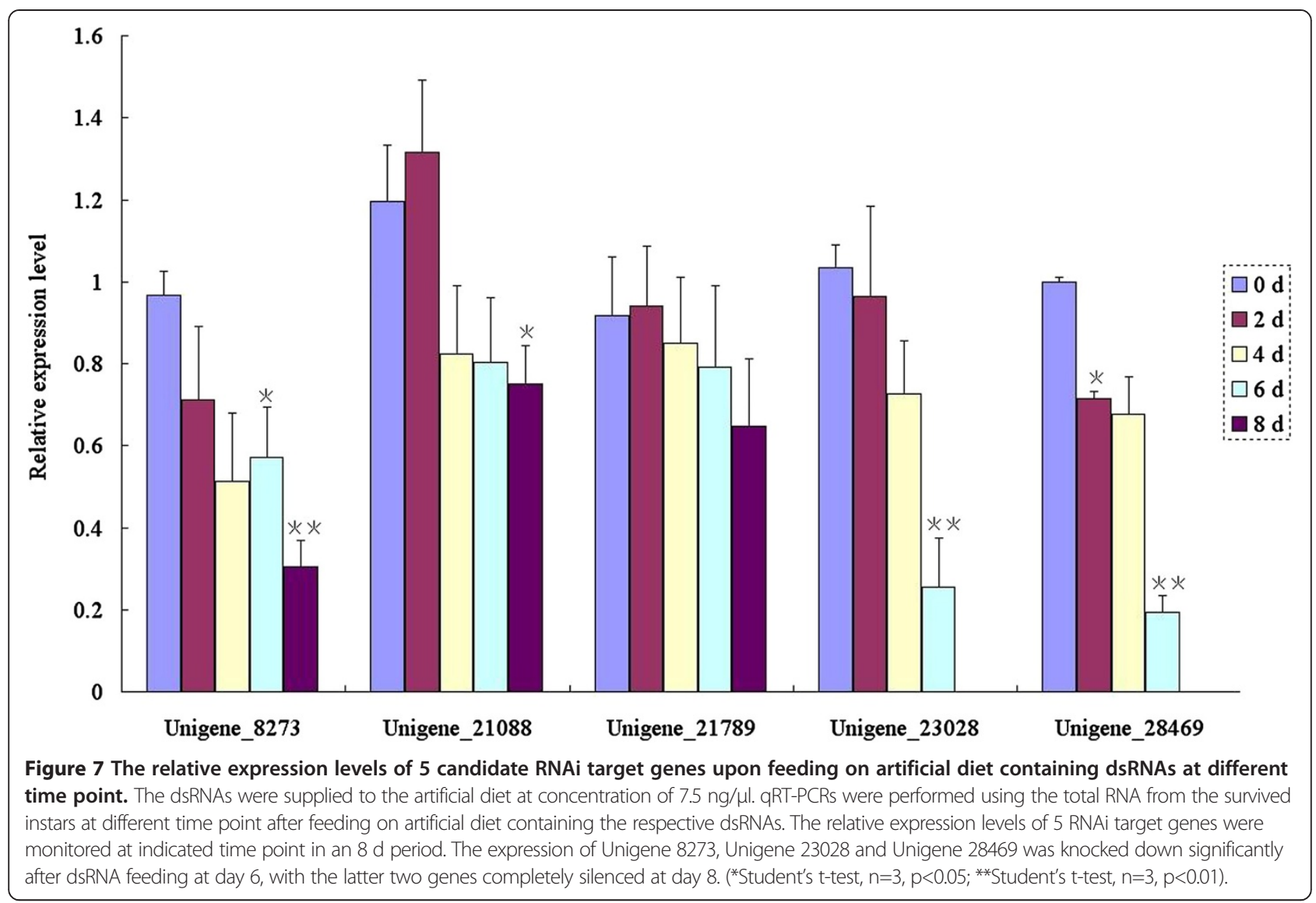

28469 and 29698 would be good RNAi targets for grain aphid control through plant-mediated RNAi strategy in agricultural practice.

\section{Spread of fluorescence in the whole aphid body after feeding with labelled dsRNA}

For the artificial feeding assay, the midgut is the primary target organ. Thus it would be interesting to know if the silencing signal would spread from midgut to other tissues in aphid, causing systemic RNAi. To investigate the systemic long-lasting RNAi effect, CTP labelled with Cy3 was added during the dsRNA synthesizing of unigene 23028. After removing the residual DNA and single strand RNA by DNase and RNase A digestion, the dsRNA was purified by MEGAclearTM columns (Ambion) and supplied to the artificial diet at a concentration of $7.5 \mathrm{ng} / \mu \mathrm{l}$. The fluorescence signals were observed in a $24 \mathrm{~h}$ period. As indicated in Figure 8, $2 \mathrm{~h}$ later, the fluorescence signal was mainly observed in the mouthparts, indicating the start of dsRNA feeding (Figure 8A). Three to four hours later, strong fluorescent signals were observed, mainly in the midgut with some also observed in the intestine part of the digestion system (Figure $8 \mathrm{~B}, 8 \mathrm{C}$ ). In the time period of dsRNA artificial diet feeding experiment, namely 12 , 18 or $24 \mathrm{~h}$, the fluorescent signal spread around the whole body tissues (Figure 8D). This result showed the evidence for the first time that fluorescent labelled 23028 dsRNA could be taken up through the digestive system and was not localized to the midgut (the site of dsRNA delivery) and temporally limited. It demonstrates that dsRNA could penetrate the perimicrovillar membrane and spread to the whole body tissues in grain aphid, then lead to a down-regulation/knock out of the target gene expression and finally to the development retarding and/or death (Figures 6, 7).

\section{Discussion}

Following with the release of the first pea aphid genome in 2010, the aphid community is gearing up for generating genome information for additional aphid species such as green peach aphid, green bug, Russian wheat aphid, potato and cotton aphid, and the pursuit of highresolution comparative genomic and evolutionary analyses [37]. However, a comprehensive view of the molecular profile of grain aphid, a diverged species from pea aphid with host plants adaptation mainly to cereal crops has not been documented so far. The alimentary canals of aphids play a crucial role in ingestion and digestion. This study compared two transcriptomic profiles of the alimentary 


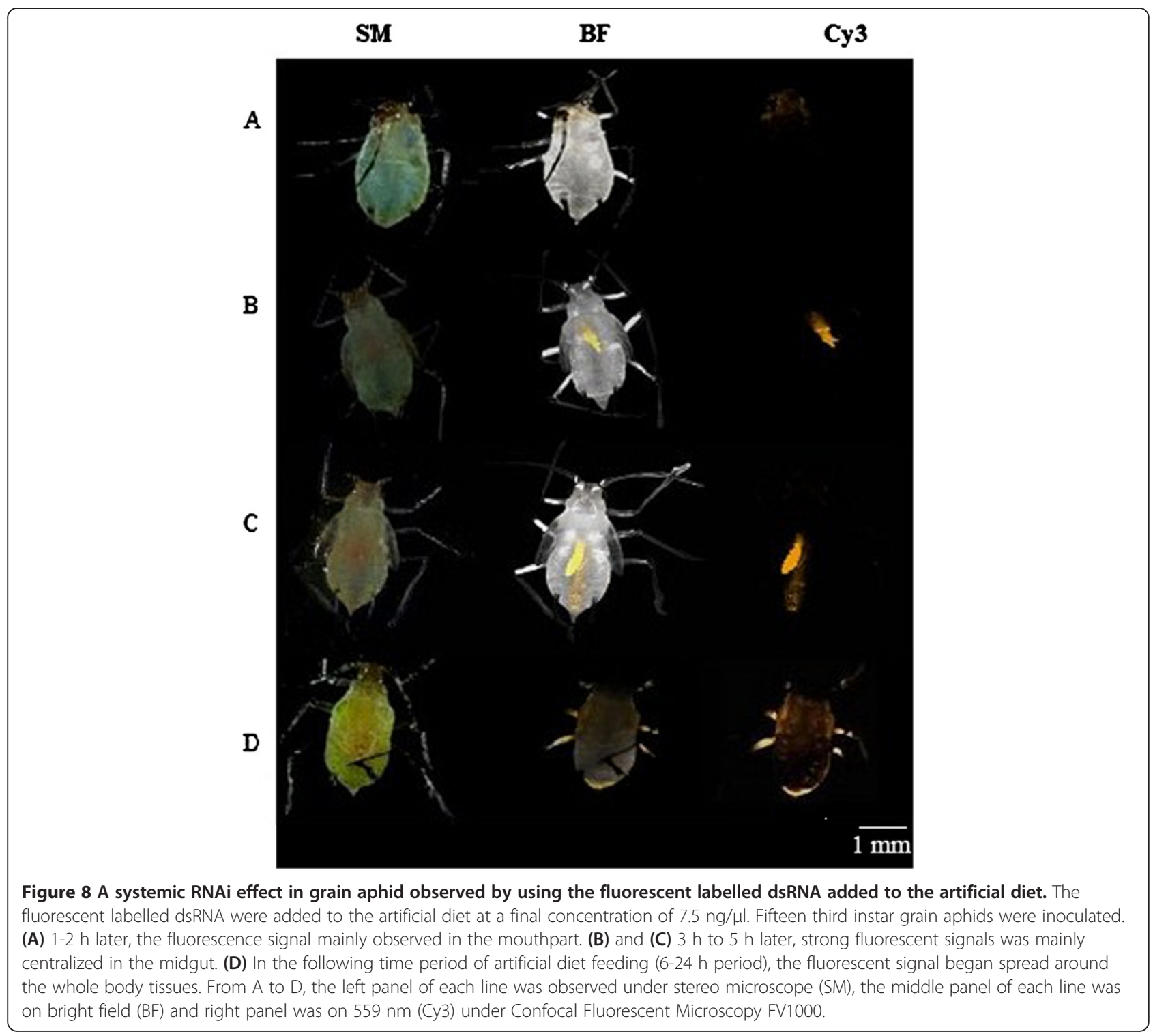

canals of grain aphid, either with, or without the influence of feeding on wheat plants. 5490 unigenes were found to be differentially expressed, with 2918 genes up-regulated and 2572 genes down-regulated (See Additional file 1). While there were no significantly enriched cellular components showing differential expression, the genes involved in three molecular functions were found to be enriched upon feeding such as NADH dehydrogenase activity, oxidoreductase activity, and genes involved in eight biological processes were significantly enriched upon feeding on wheat plants such as generation of precursor metabolites and energy, oxidation-reduction process, energy derivation by oxidation of organic compounds and etc. (See Additional file 2). Furthermore, among the 2021 unigenes involved in 'Metabolic pathways', 420 showed differential expression, which accounted for $18.09 \%$ of total DEGs (2322) with pathway annotation (See Additional file 3).
These results suggested that upon feeding on wheat plants, these diversified genes and/or pathways played important roles in nutrition ingestion and digestion in aphid. The obtained transcriptome profile of the alimentary canal of grain aphid upon feeding on wheat plants facilitates our understanding of the molecular mechanisms underlying feeding, ingestion and digestion.

For species without sufficient genomic information, transcriptome profiling through RNA-seq could provide a mass-screening approach to identify candidate genes for RNAi targeting for potential application in pest insect control [32]. In this study, we chose the candidate RNAi targets based on comparison of the transcriptome profiling data of the alimentary canals of grain aphids pre- and post feeding on wheat plants. Among 5490 differentially expressed unigenes detected in grain aphid upon feeding, 16 candidate genes which were highly expressed (based on 
their RPKM values) in both Chuli and Duizhao, or only expressed in one treatment, were selected for the dsRNA artificial diet feeding assay (Table 2). Of these, 5 were ultimately identified as effective potential RNAi targets (Figure 6 and Figure 7). Successful and unsuccessful RNAi experiments have been also observed in a number of lepidopteran species [38]. In lepidoptera, out of 130 genes used for the dsRNA artificial diet feeding analysis, only $38 \%$ were silenced at high levels while $48 \%$ and $14 \%$ of the genes failed to be silenced or were silenced at low levels, respectively. The reason for the low rate of silencing may be due to the efficiency of RNAi-mediated knockdown appears to depend on the identity and nature of the target gene. The type of gene to be silenced can significantly affect the outcome of an RNAi experiment [38]. The susceptibility of different targets to RNAi effects also shows considerable variation in model species [9]. Some targets have proved to be completely refractory to suppression as observed in most of the neuronal expressed genes in $C$. elegans [36]. In this study, we observed the same phenomena and noticed that not all the dsRNAs of the candidate unigenes tested could lead to the knock-down of target genes and the developmental stunting or death of aphids. Among the selected 16 up- and down- regulated genes, only 5 of them were effective RNAi targets (Figure 6). As indicated in Table 2, except for unigenes 23028 and 29698 which only expressed in Chuli or Duizhao, respectively, the rest of RNAi target genes such as 21088, 21789 and 28469 were highly expressed in the alimentary canal in either Chuli or Duizhao or both treatments (Table 2). This suggested that the dsRNAs of highly expressed genes involved in ingestion and digestion might achieve more effective knock-down or silencing of the target genes and higher mortality of aphid.

Furthermore, for potential RNAi target selection in plant-mediated RNAi for aphid control, we need to keep in mind that the silencing must be highly specific for the intended target gene. The risk of unintended cross-species silencing would be a major biosafety concern in the future application of RNAi mediated aphid resistance. It is therefore obvious to select highly insect-specific genes with no good match to sequences in non-target organisms such as the donor plants for engineering, the natural enemies of the target pest or humans and animals that may consume the crop as food or feed. Of the five effective RNAi targets identified in this study, three unigenes 21789, 28469 and 29698 had no orthologs identified (Table 2), suggesting they were novel genes/transcripts identified in grain aphid for the first time, and could be potential RNAi target genes in managing aphid resistance in transgenic wheat plants. Therefore, massive screening and careful selection of the RNAi target genes would be essential for the future application of plant-mediated RNAi for aphid control.
In artificial feeding assays, the concentrations of dsRNAs may be a determining factor on the final RNAi effect, either on in vitro artificial feeding assay or in planta through plant-mediated RNAi for aphid control. The occurrence of RNAi effect either through feeding or injection depends on both the gene targeted and the insect species investigated. For example, a great variation exists among different lepidopteran species with respect to their sensitivity to systemic RNAi and variable levels of silencing can occur at very different concentrations of dsRNA. It is not true that exceeding the optimal concentration results in more silencing $[25,38,39]$. In a few species, including H. cecropia, Antheraea pernyi and $M$. sexta, high levels of silencing can be achieved by application of very low amounts of dsRNA (less than $10 \mathrm{ng}$ per mg tissue in injection experiment) [40-42]. For the dsRNA feeding experiments, 15 insect species (representing 7 different orders), were investigated, and the amount of dsRNA applied varied from $5.4 \mathrm{ng} / \mathrm{cm}^{2}$ to $80 \mu \mathrm{g}$ (no indication of the concentration) [12]. In pea aphid, lethal effects were achieved with different concentrations of dsRNA or SiRNA used for injection or feeding. For example, each aphid was injected with $5 \mathrm{nl}$ C002 SiRNA (10 $\mu \mathrm{g} / \mu \mathrm{l})$ led to knockdown of $\mathrm{COO2}$ gene [22]. So far, doseresponse relationships using lower concentration of dsRNA to establish the sensitivity to RNAi has not been reported in insects [38]. In this study, by using $\mathrm{SaCOO2}$ as a positive control, a clear dose-response relationship was established between the relative lower concentration of dsRNA and the aphid's sensitivity to RNAi in artificial diet feeding bioassay in grain aphid (Figure 5). Based on this experiment, when dsRNAs were added at a concentration of $7.5 \mathrm{ng} / \mu \mathrm{l}$, a lethal effect had been achieved for 5 potential RNAi target genes, with significant effects on mortality observed $4 \mathrm{~d}$ after feeding with dsRNAs targeting unigenes such as 23028, 29698 and $2 \mathrm{~d}$ for 28469, which performed even better than COO2 dsRNA (Figure 6). The lethal efficacy of the relative low concentration of dsRNA $(7.5 \mathrm{ng} / \mu \mathrm{l})$ observed in this study will not only maintain the minimal risk of non-specific effects but also facilitate the application of plant-mediated RNAi silencing of these target genes for aphid control in agricultural practice.

Systemic RNAi encompasses both cell-autonomous and environmental RNAi in which the silencing signal is transported from the cell in which the dsRNA is applied or expressed to other cells or tissues [12]. Small RNA pathways are highly conserved in animals including aphids $[12,43]$. However, although orthologs of RNA-dependent RNA polymerase (RdRP) are present in nematodes, plants and higher animals, the presence of RdRP was never confirmed in insects $[20,28,44]$. Therefore, the absence of dsRNA amplification and RdRP in insects suggests that gene knockdown effects exhibited by injecting and/or 
feeding dsRNA to insects would be temporary, limited to cells that have taken up dsRNA and would require continuous input of dsRNA to persist, or in other words, systemic RNAi probably does not exist in insects $[9,45]$. Nevertheless, systemic RNAi has been demonstrated in some insect species, such as Hyalophora cecropia and $B$. mori, in which injection of dsRNA into the pupa can result in phenotypic effects in developing embryos, indicating dsRNA uptake by the developing oocytes of the pupa, and knockdown of a gene expressed in adult antenna of light brown apple moth (Epiphyas postvittana) could be achieved through feeding dsRNA to larvae, demonstrating a persistence of the RNAi signal throughout the larval and adult stages and systemic spread of RNAi signal from the gut to the antennae $[38,46]$. Successful knockdown of target genes through RNAi was also observed in pea and peach aphid [22-25], however, no direct evidence for the existence of systemic RNAi has ever been presented in aphid species. Given that MpCOO2 expression, which occurs predominantly in the salivary glands, is knocked down by up to $60 \%$ in peach aphid upon feeding on dsRNA transgenic tobacco plants, the silencing signal appears to spread between organs in aphid species [26]. In this study, CTP labelled with Cy3 was added during the synthesis of dsRNA designed to unigene 23028 and the long-lasting RNAi effect was observed. The fluorescence signal were observed first in the mouthparts, and then centralized in the midgut and finally it spread through the whole body (Figure 8). BLAST analysis of the transcriptome data obtained in this study against the public databases revealed the presence of some RNAi core machinery elements such as Argonaute-2B, Dicer-1, SID-1 and also TAR RNA binding protein (TRBP), which function in assisting the RISC formation (data not shown). However, the mechanisms underpinning the spread of fluorescence signal still need to be further investigated, for example, the spread of fluorescence signal is through the aphid's circulatory system or the in vivo amplification of siRNA, in which cells or tissues the target genes were silenced, and whether the proposed receptor mediated endocytosis or the transmembrane channelmediated uptake are the mechanism leading to the persistence of RNAi effect.

Nevertheless, we here identified 5 novel and effective RNAi targets in grain aphid based on comparison of the transcriptome profiles of the alimentary canal of grain aphid upon feeding on wheat plant and presented the first evidence that fluorescent labelled dsRNA could be taken up through the digestive system and was not localized to the midgut (the site of dsRNA delivery) and temporally limited, could spread to the whole body tissues in grain aphid, then lead to a down-regulation/knock out of the target gene expression and finally to the development retarding and/or death of grain aphid. This laid a fundamental basis for future plant-mediated RNAi for aphid control in agriculture.

\section{Conclusions}

In this study, we performed transcriptome assembly and gene expression analysis of the alimentary canals of preand post-feeding grain aphids on wheat plants using Illumina's RNA sequencing. We obtained 30,427 unigenes which were expressed in grain aphid alimentary canal. Furthermore, of 5490 unigenes differentially expressed upon feeding, diverse genes and/or pathways involved were identified. Moreover, among the selected 16 up- or down-regulated unigenes for dsRNA artificial diet feeding test, the dsRNAs of 5 unigenes led to higher mortality and developmental stunting due to the downregulation of the target gene expression. Finally, by adding the fluorescent labelled dsRNA into the artificial diet, the spread of fluorescent signal in the whole body was observed. The obtained transcriptome profile of the alimentary canal of grain aphid upon feeding on wheat plants would facilitate our understanding the molecular mechanism underlying feeding, ingestion and digestion. Furthermore, the identified 5 novel and effective RNAi target genes would provide a fundamental basis for aphid control in wheat through plant mediated RNAi strategy.

\section{Methods}

\section{Plant and insect materials}

Wheat: 15-20 seeds of wheat cv. Kenong 199 (a low susceptible wheat variety to aphid infestation) were planted in pots (10 $\mathrm{cm}$ diameter) that were kept in culture room at $22^{\circ} \mathrm{C}, 40 \%-60 \%$ relative humidity and a photoperiod of 16:8 (L:D). Plants at the two-leaf stage in each pot enclosed in Perspex tubes which were sealed with porous plastic sheeting were used for the aphid bioassay.

Aphids: Apterous adult grain aphids (S. avenae) derived from a single clonal lineage reared on wheat plants was placed in cages for $24 \mathrm{~h}$ to produce nymphs. Ten neonate nymphs produced in the $24 \mathrm{~h}$ period were transferred into fresh wheat plants in each pot. 12 days later, the third instars of these aphids were selected and subjected to artificial diet feeding experiment.

\section{Wheat plant feeding assay and dissection of aphid alimentary canal upon feeding}

The aphids derived from a single clonal lineage were used for the following analyses. Four hundred grain aphids at different development stages, for example, 80 first instars, 80 second instars, 80 third instars, 80 fourth instars and 80 adults were selected and kept in a glass vial for in vitro bioassay without any artificial diet for a period of $6 \mathrm{~h}$. Then, half of them was moved to fresh wheat plants and subjected to feeding. Six hours later, 
the aphid alimentary canal from pre- and post-feeding aphid treatments were dissected from the whole body on ice under the microscope. The samples were immediately frozen in liquid nitrogen, and stored at $-80^{\circ} \mathrm{C}$ before RNA extraction.

\section{Sample collection and RNA isolation}

Total RNA was isolated using a Qiagen RNA Extraction kit according to the manufacturer's instructions (New England BioLabs). It was treated with RNase-free DNase I for $30 \mathrm{~min}$ at $37^{\circ} \mathrm{C}$ to remove residual DNA, and mRNA was isolated from DNA-free total RNA using Dynabeads mRNA Purification Kit (Invitrogen).

CDNA synthesis, sequencing and data analysis of RNA-seq Beads with Oligo $(\mathrm{dT})$ were used to isolate poly(A) mRNA after total RNA collected from grain aphid guts pre- and post feeding on wheat plants. Fragmentation buffer was added for interrupting mRNA to short fragments. Taking these short fragments as templates, random hexamerprimer was used to synthesize the first-strand cDNA. The second-strand cDNA was synthesized using buffer, dNTPs, RNaseH and DNA polymerase I, respectively. Short fragments were purified with QiaQuick PCR extraction kit and resolved with elution buffer for end reparation and the natural addition of the poly(A). Then the short fragments were joined with sequencing adapters. After the agarose gel electrophoresis, the suitable fragments were selected as templates for the PCR amplification. At last, the library was sequenced using Illumina HiSeq 2000. Short read sequences were de novo assembled using SOAP de novo program [47]. Short clean reads were loaded into computer and the unambiguous sequence fragments were obtained as contigs. Then the reads were realigned onto the contigs according to the paired-end information and the unique contigs were joined into scaffolds. Finally, the intra-scaffold gaps were filled using the paired-end extracted reads. Those sequences which can not extend to any direction were unigenes. The unigenes were analysed using BLASTX against the database of $\mathrm{nr}$, Swiss-Prot, COG, GO and KEGG for functional annotations. The expression levels of unigenes were estimated by RPKM method [48].

\section{dsRNA synthesis}

dsRNAs were synthesized using the MEGAscript RNAi kit (Ambion, Huntingdon, UK) according to manufacturer's instructions. $T_{7}$ promoter sequences were tailed to each end of DNA template by PCR amplifications. Double stranded GFP (dsGFP) was generated using pPigbacA3EYFP as template and was used as a negative control in the experiments. All the primer sequences were listed in Table 3. Template DNA and single-stranded

Table 3 Primer sets used for qRT-PCR analysis of the selected candidate genes upon aphid feeding on wheat plants and in vitro dsRNA synthesis of 16 candidates

\begin{tabular}{|c|c|c|}
\hline Unigene no. & Forward primer & Reverse primer \\
\hline Unigene_6994 & TAATACGACTCACTATAGGGAGCTGAAAAGTGAAATGATGGTGGTC & TAATACGACTCACTATAGGGTTGCCAAACTGGAAAATCG \\
\hline Unigene_ 8273 & TAATACGACTCACTATAGGGAGTGCGTCAGATAGTCCGGCACC & TAATACGACTCACTATAGGGCACCATTCAAATCCGTTTCTTACAGC \\
\hline Unigene_ 8279 & $\underline{\text { TAATACGACTCACTATAGGGAGAAAGCAATGCTGTGGCAGAAAC }}$ & $\underline{\text { TAATACGACTCACTATAGGGGTGGTCGTTCTTCAGTGATGG }}$ \\
\hline Unigene_11975 & $\underline{\text { TAATACGACTCACTATAGGGAGCGCTGTTGGTGCTGGTGGTGATG }}$ & TAATACGACTCACTATAGGGTCGTTGGACGGTTTGGTCGATGTCT \\
\hline Unigene_21088 & TAATACGACTCACTATAGGGAGGTTTAACGAATCGGACCATCAGGAA & $\underline{\text { TAATACGACTCACTATAGGGAAAATATGATCGCCTCAAGGGGACT }}$ \\
\hline Unigene_21789 & $\underline{\text { TAATACGACTCACTATAGGGAGTACCGTCCGCAAATGGTTGG }}$ & TAATACGACTCACTATAGGGTCCGAAGTCACATGTTCGCA \\
\hline Unigene_23028 & TAATACGACTCACTATAGGGAGGTTATTGTTGAACCCTTCTGACACG & TAATACGACTCACTATAGGGGAAGGATTAGACGATATTTGGGTG \\
\hline Unigene_23042 & TAATACGACTCACTATAGGGAGGTTCCATGACAAGCCGGATAC & $\underline{\text { TAATACGACTCACTATAGGGGACTCAAGTGCCTGGTGGGT }}$ \\
\hline Unigene_23235 & TAATACGACTCACTATAGGGAGGGTGCCCGACTCGGTITCTCC & TAATACGACTCACTATAGGGGCTGCCCAAGCCAACATCCAC \\
\hline Unigene_26956 & TAATACGACTCACTATAGGGAGCCGTGATTCTCCTGCGTCTGCT & TAATACGACTCACTATAGGGAGTCTTCGCCACCGCCGTT \\
\hline Unigene_27357 & TAATACGACTCACTATAGGGAGATGGTTTTATGGTTGGCTTTAGTCCAG & TAATACGACTCACTATAGGGCCGCGTTCGCATTTCGTTT \\
\hline Unigene_27882 & TAATACGACTCACTATAGGGAGAGGTATCACCCGCCGTACC & TAATACGACTCACTATAGGGGAACAGCTGGTTCTGCGAAA \\
\hline Unigene_28447 & TAATACGACTCACTATAGGGAGTGGCCCGTACGACACACCGA & TAATACGACTCACTATAGGGCGGACGATGTGCCGGGTGAC \\
\hline Unigene_28469 & TAATACGACTCACTATAGGGAGCAAATGAAACGCCGTATTTGATAA & TAATACGACTCACTATAGGGCGTGCCTACCGTATTCGACAAT \\
\hline Unigene_28555 & TAATACGACTCACTATAGGGAGGGGTTAGACTTGCCCGAAACTGATG & TAATACGACTCACTATAGGGTCCATGTTGGCAGTCCAACCGT \\
\hline Unigene_29698 & TAATACGACTCACTATAGGGAGCGTCGCCTTGGTGAGCCTTAC & $\underline{\text { TAATACGACTCACTATAGGGCGGCGGACGGGTGAGTAATG }}$ \\
\hline Actin & CCGAAAAGCTGTCATAATGAAGACC & GGTGAAACCTTGTCTACTGTTACATCTTG \\
\hline GFP & $\underline{\text { TAATACGACTCACTATAGGGAGGCAGTGCTTCAGCCGCTACCC }}$ & TAATACGACTCACTATAGGGCCTTGATGCCGTTCTTCTGCTTGTC \\
\hline
\end{tabular}

Note: $T_{7}$ promoter sequences were tailed to each $5^{\prime}$ end of primers and underlined. The sequences without $\mathrm{T}_{7}$ promoter sequence tails were used for qRT-PCR analysis of the selected candidate genes upon aphid feeding on wheat plants. 
RNA were removed from the transcription reaction by DNase I and RNaseA treatment. dsRNA was purified using MEGAclearTM columns (Ambion) and eluted in $100 \mu \mathrm{l}$ nuclease free water. dsRNA concentrations were measured using Biophotometer (Eppendorf, Germany).

\section{Fluorescent labelled dsRNA to observe the RNAi effect}

The dsRNA synthesis procedure was the same as described above except that $0.25 \mathrm{ml} 10 \mathrm{mM}$ fluorescent dCTP labelled with Cy3 was added, taking advantage of character that $\mathrm{T}_{7}$ RNA polymerase could take dNTP as substrates for synthesis RNA [49]. Then the labelled dsRNA was purified by using MEGAclearTM columns (Ambion) and used as supplement to an artificial diet at a concentration of $7.5 \mathrm{ng} / \mu \mathrm{l}$. The aphids fed with $\mathrm{Cy} 3 \mathrm{la}$ belled dsRNA were observed under Confocal Fluorescent Microscopy FV1000 (Olympus) every $2 \mathrm{~h}$ in a $24 \mathrm{~h}$ period.

\section{Insect bioassay}

The artificial diet bioassay was performed according to the following procedure. Liquid artificial diet was prepared as described by Whyard et al. (2009) [23] and filtered through $2 \mu \mathrm{m}$ membrane, and dispensed in $200 \mu \mathrm{l}$ aliquots and stored at $-20^{\circ} \mathrm{C}$ before the artificial diet feeding assay. Glass vials $(2 \mathrm{~cm}$ in diameter) for aphid artificial double-membrane feeding assay were sterilized and one opening completely sealed with parafilm before sample application. $50 \mu \mathrm{l}$ of test samples containing either nuclease-free water or dsRNA were added to the $1 \mathrm{ml}$ artificial diet to the final concentration of $0,3,5$ and $7.5 \mathrm{ng} / \mu \mathrm{l}$, respectively. $200 \mu \mathrm{l}$ aliquots of samples were pipetted onto the parafilm and another layer stretched on top to form a sachet and made sure the liquid diet distributed evenly. Fifteen third instar aphids were added per vial with a fine paintbrush. Then, another opening was covered with a piece of sterilized gauze. At least 3 replicates were set up for each experimental group. The bioassay vials were put with the opening with gauze upside and incubated at $22^{\circ} \mathrm{C}-24^{\circ} \mathrm{C}$, $40 \%-60 \%$ relative humidity and a photoperiod of $16: 8$ (L:D). For each treatment, the number of survival aphids was counted every $2 \mathrm{~d}$ in an $8 \mathrm{~d}$ period. The data were analyzed using one-way ANOVA to investigate the effects of the dsRNA treatment on mortality of aphids compared to the untreated control ("Student's t-test, $\mathrm{n}=3, \mathrm{p}<0.05$; **Student's t-test, $\mathrm{n}=3, \mathrm{p}<0.01$ ).

\section{Quantitative real-time PCR (qRT-PCR)}

Expression levels of the 16 up- or down- regulated selected unigenes in grain aphid upon feeding on wheat plants according to the RPKM were re-evaluated by qRTPCR. The sequences of primer sets were provided in Table 3 except for the $T_{7}$ promoter sequences were not added. A qRT-PCR assay for multiple genes was performed with the SYBRH Premix Ex Taq TM II (TaKaRa). Grain aphid actin expression levels were used to normalize $C t$ values obtained for each gene. qRT-PCR was carried out using a Mastercycler ep realplex instrument (Eppendorf). Data analysis methods were described as the reference [50]. To assess the extent of RNAi, RNA was extracted from pools of 10 dsRNA-treated and survived aphids using a Qiagen RNA Extraction kit. Primer sets were synthesized as listed in Table 3 with no $T_{7}$ promoter sequences tailed. The samples were then treated with DNAase I (Invitrogen) to remove any genomic DNA contamination, and were used with Superscript II reverse transcriptase (Invitrogen) to make first strand cDNA using random primers. qRT-PCR reactions and statistical analysis were the same with mentioned above except for grain aphid actin expression level was used to normalize $C t$ values obtained for each unigene.

\section{Additional files}

Additional file 1: Summary of 5490 DEGs and their annotations. The relative expression levels of DEGs and their annotations in the nr, COG, GO, and KEGG public databases were summarized. Among the 5490 differentially expressed genes, only 3805 were annotated in one of the above public databases.

Additional file 2: GO terms enriched in the differentially expressed genes. The results were summarized in three main categories: biological process, cellular component and molecular function. GO analysis showed that three molecular functions were found to be enriched at $p<0.05$ level, and eight biological processes were significantly enriched at $p<0.05$ level in the alimentary canals of grain aphid upon feeding on wheat plants.

Additional file 3: KEGG pathways enriched in the differentially expressed genes. KEGG pathway analysis showed that 420 unigenes which are involved in 'Metabolic pathways' showed differentially expressed manner, accounting for $18.09 \%$ of total DEGs (2322) with pathway annotation.

\section{Abbreviations}

BLAST: Basic local alignment search tool; COG: Clusters of orthologous groups; DEGs: Differentially expressed genes; dsRNA: Double-stranded RNA; ESTs: Expressed sequence tags; GO: Gene ontology; KEGG: Kyoto encyclopedia of genes and genomes; Nr: Non-redundant protein database; Nt: Nucleic acid database; qPCR: Quantitative polymerase chain reaction; RNAi: RNA interference; RPKM: Read per kb per million; RT-PCR: Reversetranscript polymerase chain reaction.

\section{Competing interests}

The authors declare that no competing interests exist. The funding organizations had no role in study design, data collection and analysis, decision to publish, or preparation of the manuscript.

\section{Authors' contributions}

Conceived and designed the experiments: LQX, YZM and HDJ. The experiments were performed by MZ, HW and DHW. YWZ and QG analyzed the data. The manuscript was written by LQX, YZM and HDJ. All authors read and approved the final version of the manuscript.

\section{Acknowledgement}

We would like to give our thanks to Prof. Jianmin Wan's lab for helping us with the Confocal Fluorescent Microscopy analysis. This work was supported by the Research Initiative on Development of Disease and Insect Resistance Transgenic Wheat Plants from the Ministry of Agriculture of China (grant no. 2013ZX08002-001, 2014ZX0800201B), Natural Science Foundation of China (grant no. 31171618, 31371702) and the Chinese State Key Laboratory for 
Biology of Plant Diseases and Insects (grant no. SKLOF201307). Rothamsted Research receives grant-aided support from the Biotechnology and Biological Sciences Research Council (BBSRC) of the UK.

\section{Author details}

'Institute of Crop Sciences, Chinese Academy of Agricultural Sciences (CAAS), 12 Zhongguancun South Street, Beijing 100081, China. ${ }^{2}$ Beijing Genomics Institute-Shenzhen (BGI-Shenzhen), Chinese Academy of Sciences, Shenzhen 518083, China. ${ }^{3}$ Rothamsted Research, Harpenden, Hertfordshire AL5 2JQ, UK.

Received: 31 January 2013 Revised: 20 February 2013

Accepted: 9 August 2013 Published: 16 August 2013

\section{References}

1. Xia LQ, Ma YZ, He Y, Jones HD: GM wheat development in China: current status and challenges to commercialization. J Exp Bot 2012, 63:1785-1790.

2. International Aphid Genomics Consortium: Genome sequence of the pea aphid Acyrthosiphon pisum. PLoS Biol 2010, 8:e1000313.

3. Blackman RL, Eastop VF: Aphids on the world's crops. An identification and information guide. Hoboken, New Jersey: Wiley, John \& Sons, Incorporated; 1984:476.

4. Oerke EC: Estimated crop losses in wheat. In Crop production and crop protection: estimated losses in major food and cash crops. Edited by Oerke EC, Dehne HW, Schonbeck F, Weber A. Amsterdam: Elsevier; 1994:179-296.

5. Morrison WP, Peairs FB: Response model concept and economic impact. Response model for an introduced pest-the Russian wheat aphid. Lanham, MD: Entomological Society of America; 1998

6. Zhang $Y$ J, Jiang $Y Y$, Feng $X D$, Xia B, Zeng J, Liu Y: Occurring trends of major crop pests in national significances in 2009. China Plant Prot 2009, 29:33-36.

7. Stoger E, Williams S, Christou P, Down RE, Gatehouse JA: Expression of the insecticidal lectin from snowdrop (Galanthus nivalis agglutinin; GNA) in transgenic wheat plants: effects on predation by the grain aphid Sitobion avenae. Mol Breeding 1999, 5:65-73.

8. Yu XD, Pickett J, Ma Y, Bruce T, Napier J, Jones HD, Xia LQ: Metabolic engineering of plant-derived (E)- $\beta$-farnesene synthase genes for a novel type of aphid-resistant genetically-modified crop plants. J Integr Plant Biol 2012, 54:282-299.

9. Price DRG, Gatehouse JA: RNAi-mediated crop protection against insects. Trends Biotechnol 2008, 26:393-400.

10. Baum JA, Bogaert T, Clinton W, Heck GR, Feldmann P, llagan O, Johnson S, Plaetinck G, Munyikwa T, Pleau M: Control of coleopteran insect pests through RNA interference. Nat Biotechnol 2007, 25:1322-1326.

11. Mao YB, Cai WJ, Wang JW, Hong GJ, Tao XY, Wang LJ, Huang YP, Cen XY: Silencing a cotton bollworm P450 monooxygenase gene by plantmediated RNAi impairs larval tolerance of gossypol. Nat Biotechnol 2007, 25:1307-1313.

12. Huvenne H, Smagghe G: Mechanisms of dsRNA uptake in insects and potential of RNAi for pest control: a review. J Insect Physiol 2010, 56:227-235.

13. Meister $G$, Tuschl T: Mechanisms of gene silencing by double-stranded RNA. Nature 2004, 431:343-349.

14. Fire AZ: Gene silencing by double-tranded RNA (Nobel Lecture). Angew Chem Int Edit 2007, 46:6966-6984.

15. Jinek M, Doudna JA: A three-dimensional view of the molecular machinery of RNA interference. Nature 2008, 457:405-412.

16. Siomi H, Siomi MC: On the road to reading the RNA-interference code. Nature 2009, 457:396-404.

17. Whangbo JS, Hunter CP: Environmental RNA interference. Trends Genet 2008, 24:297-305.

18. Van Roessel P, Brand AH: Spreading silence with Sid. Genome Biol 2004, 5:208.

19. Grishok A: RNAi mechanisms in Caenorhabditis elegans. Febs Lett 2005, 579:5932-5939.

20. Jose AM, Hunter CP: Transport of sequence-specific RNA interference information between cells. Annu Rev Genet 2007, 41:305-330.

21. Xu W, Han Z: Cloning and phylogenetic analysis of sid-1-like genes from aphids. J Insect Sci 2008, 8:30

22. Mutti NS, Park Y, Reese JC, Reeck GR: RNAi knockdown of a salivary transcript leading to lethality in the pea aphid. Acyrthosiphon pisum. J Insect Sci 2006, 6:38.
23. Whyard $S$, Singh $A D$, Wong $S$ : Ingested double-stranded RNAs can act as species-specific insecticides. Insect Biochem Molec 2009, 39:824-832.

24. Jaubert-Possamai S, Le Trionnaire G, Bonhomme J, Christophides GK, Rispe C, Tagu D: Gene knockdown by RNAi in the pea aphid Acyrthosiphon pisum. BMC Biotechnol 2007, 7:63.

25. Shakesby AJ, Wallace IS, Isaacs HV, Pritchard J, Roberts DM, Douglas AE: A water-specific aquaporin involved in aphid osmoregulation. Insect Biochem Molec 2009, 39:1-10.

26. Pitino M, Coleman AD, Maffei ME, Ridout CJ, Hogenhout SA: Silencing of aphid genes by dsRNA feeding from plants. PLoS One 2011, 6:e25709.

27. Bhatia V, Bhattacharya R, Uniyal PL, Singh R, Niranjan RS: Host generated siRNAs attenuate expression of serine protease gene in myzus persicae. PLoS One 2012, 7:e46343.

28. Tomoyasu Y, Miller SC, Tomita S, Schoppmeier M, Grossmann D, Bucher G: Exploring systemic RNA interference in insects: a genome-wide survey for RNAi genes in tribolium. Genome Biol 2008, 9:R10.

29. Wang Z, Gerstein M, Snyder M: RNA-Seq: a revolutionary tool for transcriptomics. Nat Rev Genet 2009, 10:57-63.

30. Shen GM, Dou W, Niu JZ, Jiang HB, Yang WJ, Jia FX, Hu F, Cong L, Wang JJ: Transcriptome analysis of the oriental fruit fly (Bactrocera dorsalis). PLoS One 2011, 6:e29127.

31. Xue J, Bao YY, Li B, Cheng YB, Peng ZY, Liu H, Xu HJ, Zhu ZR, Lou YG, Cheng JA: Transcriptome analysis of the brown planthopper Nilaparvata lugens. PLoS One 2010, 5:e14233.

32. Wang $Y$, Zhang H, Li H, Miao X: Second-generation sequencing supply an effective way to screen RNAi targets in large scale for potential application in pest insect control. PLOS One 2011, 6:e18644.

33. Silva CP, Silva JR, Vasconcelos FF, Petretski MDA, DaMatta RA, Ribeiro AF, Terra WR: Occurrence of midgut perimicrovillar membranes in paraneopteran insect orders with comments on their function and evolutionary significance. Arthropod Struct Dev 2004, 33:139-148.

34. Wang P, Granados RR: Molecular structure of the peritrophic membrane (PM): identification of potential PM target sites for insect control. Arch Insect Biochem 2001, 47:110-118.

35. Pertea G, Huang X, Liang F, Antonescu V, Sultana R, Karamycheva S, Lee Y, White J, Cheung F, Parvizi B: TIGR gene indices clustering tools (TGICL): a software system for fast clustering of large EST datasets. Bioinformatics 2003, 19:651-652.

36. Kennedy S, Wang D, Ruvkun G: A conserved siRNA-degrading RNase negatively regulates RNA interference in C. elegans. Nature 2004, 427:645-649.

37. International Aphid Genomics Consortium: Aphid White Paper II: proposal to complete development of the aphid model. 2010, IAGC-White Paper II-FINAL VERSION-September $13^{\text {th }} 2010$.

38. Terenius O, Papanicolaou A, Garbutt JS, Eleftherianos I, Huvenne H, Kanginakudru S, Albrechtsen M, An C, Aymeric JL, Barthel A: RNA interference in Lepidoptera: an overview of successful and unsuccessful studies and implications for experimental design. I Insect Physiol 2011, 57:231-245.

39. Meyering-Vos M, Muller A: RNA interference suggests sulfakinins as satiety effectors in the cricket Gryllus bimaculatus. J Insect Physiol 2007, 53:840-848.

40. Bettencourt $\mathrm{R}$, Terenius $\mathrm{O}$, Faye I: Hemolin gene silencing by ds-RNA injected into cecropia pupae is lethal to next generation embryos. Insect Mol Biol 2002, 11:267-271.

41. Hirai MY, Yano M, Goodenowe DB, Kanaya S, Kimura T, Awazuhara M, Arita M, Fujiwara T, Saito K: Integration of transcriptomics and metabolomics for understanding of global responses to nutritional stresses in Arabidopsis thaliana. Proc Natl Acad Sci U S A 2004, 101:10205-10210.

42. Terenius O, Bettencourt R, Lee SY, Li WL, Soderhall K, Faye I: RNA interference of hemolin causes depletion of phenoloxidase activity in hyalophora cecropia. Dev Comp Immunol 2007, 31:571-575.

43. Kim VN, Han J, Siomi MC: Biogenesis of small RNAs in animals. Nat Rev Mol Cell Bio 2009, 10:126-139.

44. Richards S, Gibbs RA, Weinstock GM, Brown SJ, Denell R, Beeman RW, Gibbs R, Bucher G, Friedrich M, Grimmelikhuijzen CJP: The genome of the model beetle and pest tribolium castaneum. Nature 2008, 452:949-955.

45. Zha W, Peng X, Chen R, Du B, Zhu L, He G: Knockdown of midgut genes by dsRNA-transgenic plant-mediated RNA interference in the hemipteran insect Nilaparvata lugens. PLoS One 2011, 6:e20504.

46. Turner CT, Davy MW, MacDiarmid RM, Plummer KM, Birch NP, Newcomb RD: RNA interference in the light brown apple moth, Epiphyas 
postvittana (Walker) induced by double-stranded RNA feeding. Insect Mol Biol 2006, 15:383-391.

47. Li R, Li Y, Kristiansen K, Wang J: SOAP: short oligonucleotide alignment program. Bioinformatics 2008, 24:713-714

48. Mortazavi A, Williams BA, McCue K, Schaeffer L, Wold B: Mapping and quantifying mammalian transcriptomes by RNA-Seq. Nat Methods 2008 , 5:621-628.

49. Gaur RK, Krupp G: Modification interference approach to detect ribose moieties important for the optimal activity of a ribozyme. Nucleic Acids Res 1993, 21:21-26.

50. Livak KJ, Schmittgen TD: Analysis of relative gene expression data using real-time quantitative PCR and the 2(-Delta Delta $C(T))$ method. Methods 2001, 25:402-408.

doi:10.1186/1471-2164-14-560

Cite this article as: Zhang et al: Identifying potential RNAi targets in grain aphid (Sitobion avenae F.) based on transcriptome profiling of its alimentary canal after feeding on wheat plants. BMC Genomics 2013 14:560

\section{Submit your next manuscript to BioMed Central and take full advantage of:}

- Convenient online submission

- Thorough peer review

- No space constraints or color figure charges

- Immediate publication on acceptance

- Inclusion in PubMed, CAS, Scopus and Google Scholar

- Research which is freely available for redistribution 